\title{
Digital Tools to Promote Healthy Eating for Working-Age Individuals: A Scoping Review
}

\author{
Sibo Pan \\ Department of Industrial Design, Eindhoven University of \\ Technology \\ s.pan1@tue.nl \\ Steven Vos \\ Department of Industrial Design, Eindhoven University of \\ Technology, Fontys University of Applied Sciences \\ Eindhoven \\ s.vos@tue.nl
}

\begin{abstract}
In this scoping review, we aimed to understand current developments of digital tools for promoting healthy eating behaviors in a work context among working-age individuals and identify research gaps for future design opportunities. The papers published over the last decade (2010-2021) were searched in three databases: the Association for Computing Machinery (ACM) digital library, the interdisciplinary library Scopus, and the PubMed database. Initially, 2098 papers were identified, of which 16 papers were included in the final analysis. These 16 papers were published in 15 various conference proceedings or journals between 2010 and 2021, and mainly focused on tracking eating moment and promoting healthy food intake. Our findings showed that four types of digital tools for healthy eating promotion were commonly used, including mobile applications, wearables, service, and multicomponent (i.e., a combination between mobile apps and wearables). Moreover, we found that current digital tools made small using a range of existing working infrastructures. Future design research could focus on personalized, interactive, and playful digital tools in humancomputer interaction field with behavior change techniques and user-centered approaches to promote healthy eating behaviors in daily work routines.
\end{abstract}

\section{CCS CONCEPTS}

- Human-centered computing; • Human computer interaction (HCI); • Interactive systems and tools;

\section{KEYWORDS}

Healthy eating, office vitality, digital health, digital technology

${ }^{*}$ Corresponding author.

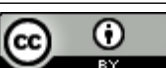

This work is licensed under a Creative Commons Attribution International 4.0 License.

Chinese CHI 2021, October 16, 17, 2021, Online, Hong Kong

(c) 2021 Copyright held by the owner/author(s).

ACM ISBN 978-1-4503-8695-1/21/10

https://doi.org/10.1145/3490355.3490356

\author{
Xipei Ren ${ }^{*}$ \\ School of Design and Arts, Beijing Institute of Technology \\ x.ren@bit.edu.cn
}

\author{
Aarnout Brombacher \\ Department of Industrial Design, Eindhoven University of \\ Technology \\ a.c.brombacher@tue.nl
}

ACM Reference Format:

Sibo Pan, Xipei Ren, Steven Vos, and Aarnout Brombacher. 2021. Digital Tools to Promote Healthy Eating for Working-Age Individuals: A Scoping Review. In The Ninth International Symposium of Chinese CHI (Chinese CHI 2021), October 16, 17, 2021, Online, Hong Kong. ACM, New York, NY, USA, 8 pages. https://doi.org/10.1145/3490355.3490356

\section{INTRODUCTION}

A healthy eating behavior commonly seems to be a key component that paves the way for individuals' vitality and health. According to the World Health Organization, an unhealthy diet is a major risk factor for a range of non-communicable diseases including obesity, diabetes and other conditions linked to cancer [14]. In addition, healthy eating habits and routines are important for populations such as workers who are at increased risk of obesity and other chronic diseases [17]. Health promotion interventions in the workplace were developed to encourage people to adopt healthpromoting behaviors, including a healthy diet [15]. In addition, considering two thirds of the daily waking time people spending on their full-time jobs [2], worksites potentially offer an important occasion on influencing eating patterns.

Recent studies related to automatic dietary monitoring and human-food interactions have shown that digital technologies present an opportunity to measure actual eating-related behaviors $[4,12,23,50]$. Eating-linked non-medical digital technologies are generally effective in detecting eating time, weight management, and healthy food consumption (fruits and vegetable) [35]. These digital technologies are designed as mobile applications (e.g. MyFitnessPal [20], Fitocracy Macros [24]) and wearable devices (e.g. motion detection during intake [25], chewing [5] and swallowing [6] detection, and digital photography [3, 29]).

Several systematic reviews have summarized that interventions (e.g. web-based, educational approaches, feedbacks, etc.) targeting both eating behavior and physical activity have effects on supporting personal weight management [7, 28, 49]. Similarly, a number of reviews and studies have found that worksite eating promotion tools could be leveraged to reduce the chance of developing obesity and overweight due to sedentary working hours $[10,48]$ as well as aiding the work-caused eating disorders [38]. In addition, some other reviews revealed that using behavior theories for reminding healthy eating during working hours [18] and providing 
feedback based on personal health assessments [39] could improve the effectiveness of worksite health-promoting interventions.

Few review studies are specifically aimed at understanding technologies and designs on healthy eating during working hours. In the present paper, we reviewed recent digital technologies to assess intake or promote occupational healthy eating behaviors. The scoping review summarized research from 2010 to 2021 on digital technology for non-medical eating purposes. Rather than focusing on the outcomes of the designs and technologies, this review aims to provide an overview on the design considerations of healthy eating digital tools. Based on this scoping review, we hope to identify the research gaps in daily eating promotion and design opportunities for promoting healthy eating behaviors in the working contexts (e.g., the office setting). In particular, we aim to 1) understand how those technologies and designs were applied for promoting occupational healthy eating; 2) identify design opportunities of future health-promoting digital tools that support healthy eating practices among working-age individuals.

\section{METHOD}

\subsection{Search and Selection}

The scoping literature review was conducted according to a methodological framework [8], involving 1) identifying the research question, 2) identifying relevant papers, 3) paper selection, 4) charting the data, 5) collating, summarizing, and reporting the results. The search included full-text research papers in English language published in peer-reviewed scientific conference proceedings or journals in the Association for Computing Machinery (ACM) digital library, the interdisciplinary library Scopus, and the PubMed database. All articles were searched for designs or technologies to promote intake assessment and healthy eating behaviors. The following search keywords were used: ("human-food interaction" OR "health informatics" OR "digital tool" OR "digital technology" OR "wearable sensor") AND ("eating” OR "diet") AND ("office" OR "workplace" OR "working hour"). We limited the publication dates of the papers to the period between 2010 and 2021 .

We only considered papers that applied digital technologies to promote healthy eating behavior in general working-age populations for non-therapeutic purposes. The work-age populations are the adults who do not have eating-related disease and exhibit eating behaviors in a working context (i.e., office). To limit the number of relevant papers, we excluded papers 1) that have therapeutic purposes or target patient populations; 2) which describe the designs or technologies for special user groups, such as children, family members, students, or the older adults; 3 ) where food is only a medium to promote a healthy lifestyle.

\subsection{Procedure and Data Analysis}

The selection process of our study was done with the following four main steps: database search, title and abstract screening, full-text screening, and snowball search. First, papers published between 2010 and 2021were searched in ACM digital library, Scopus, and PubMed. Second, the titles and abstracts were screened by two independent reviewers (the first two authors) based on the selected inclusion and exclusion criteria. Third, a snowballing procedure in the reference lists of the selected papers and the citations was manually performed to identify additional papers [52]. 21 extra papers were included as additional eligible papers. Fourth, three independent reviewers (the first three authors) performed a fulltext screening on the selected papers. Consensus was reached after deliberating discrepancies. Eventually, sixteen eligible papers were included in our final review for data synthesis. These papers were extracted in terms of publication data, objectives, theoretical underpinning, using context, and types of design and technology. The qualitative data was analyzed by two independent coders, following the thematic analysis procedure [43]. All analyzed results were discussed and agreed upon between the first two authors. Disagreements were resolved via deliberations.

\section{RESULTS}

\subsection{Study Selection}

An overview of the selection process in the various stages is visualized in Figure 1. The Preferred Reporting Items for Systematic Reviews and Meta-Analyses (PRISMA) [31] was used to guide the selection process. Our initial search identified 2098 papers from the ACM, Scopus, and PubMed databases. After removing 118 duplicates, 1980 relevant papers remained. The titles and abstracts of these papers were screened based on the selection criteria, after which 47 papers were selected as eligibility. The additional articles were retrieved from the reference list and added to the review list. Of these, papers were excluded (i) where participants were selected because of obesity or other health-related issues $(n=16)$, (ii) where peers were recruited to test prototypes $(n=5)$, (iii) where foods were used to promote physical activities or mental pleasure $(n=2)$, or (iv) where no digital tools or technology was presented $(n=29)$.

Sixteen papers are included in the final review list (shown in Table 1). Five were full-text conference articles, four were short conference articles, and seven were full-text journal articles. These papers were published in 15 various conference proceedings or journals between 2010 and 2021. These papers were published by thirteen different first authors from various continents.

\subsection{Characteristics of the Included Papers}

Objective Among the 16 included papers, 10 papers presented digital tools and designs aimed at identifying eating moments in real-life settings $[9,17,19,30,36,37,44-46,54]$, while the other papers focused on improving eating behaviors and food choice $[1,13,22,26,42,53]$ (as shown in Table 2). Specifically, regarding the 10 papers about eating moments identification, seven $[9,17,19,44-$ $46,54]$ utilized digital tools to automatically monitor daily eating time and duration. One paper [37] further predicts following eating events for users after monitoring. In two [30,36] papers eating moments were measured by distinguishing eating activities from other daily activities, such as working, speaking, and walking. In terms of improving eating patterns and food choice, two studies $[22,42]$ involved encouraging healthy food choices by scanning codes to obtain interactive information about related foods. Two other studies have promoted healthy eating habits at work [26, 53]. One study [1] focused on increasing fruit consumption in the work setting, and another study [13] used digital technology to measure food intake. 
Table 1: Overview of selected papers

\begin{tabular}{|c|c|c|c|c|c|}
\hline & Reference & $\begin{array}{l}\text { Sample } \\
\text { Size }\end{array}$ & $\begin{array}{l}\text { Design Name/ } \\
\text { Technology Type }\end{array}$ & Description & Objective \\
\hline 1 & $\begin{array}{l}\text { Alinia et al. } \\
2011[1]\end{array}$ & 124 & $\begin{array}{l}\text { Fruit basket } \\
\text { intervention with free } \\
\text { fruits in worksite }\end{array}$ & $\begin{array}{l}\text { By increasing fruit availability and } \\
\text { accessibility in the worksite to encourage } \\
\text { daily fruit intake }\end{array}$ & $\begin{array}{l}\text { Increases fruits consumption } \\
\text { during work }\end{array}$ \\
\hline 2 & $\begin{array}{l}\text { Bedri et al. } \\
2015 \text { [9] }\end{array}$ & 20 & $\begin{array}{l}\text { Outer-ear Interface } \\
\text { System }\end{array}$ & $\begin{array}{l}\text { Detect eating activities automatically by } \\
\text { measuring deformations in the ear canal } \\
\text { walls due to mastication activity }\end{array}$ & $\begin{array}{l}\text { Help to identify eating } \\
\text { moments automatically }\end{array}$ \\
\hline 3 & $\begin{array}{l}\text { Bi et al. } 2015 \\
{[13]}\end{array}$ & 53 & AutoDietary & $\begin{array}{c}\text { A wearable system to recognize food types } \\
\text { by monitoring eating process and provide } \\
\text { tailored suggestions }\end{array}$ & $\begin{array}{l}\text { Monitor daily food intake of } \\
\text { an individual precisely and } \\
\text { conveniently }\end{array}$ \\
\hline 4 & $\begin{array}{l}\text { Chung et al. } \\
2017 \text { [17] }\end{array}$ & 10 & GlasSense & $\begin{array}{c}\text { Monitoring patterns of food and facial } \\
\text { activities through load cells embedded a pair } \\
\text { of glasses }\end{array}$ & $\begin{array}{l}\text { Help to identify eating } \\
\text { moments automatically }\end{array}$ \\
\hline 5 & $\begin{array}{l}\text { Dong et al. } \\
2014[19]\end{array}$ & 43 & watch-like device & $\begin{array}{l}\text { A watch-like configuration of sensors to } \\
\text { continuously track wrist motions and } \\
\text { automatically detect periods of eating }\end{array}$ & $\begin{array}{l}\text { Help to identify eating } \\
\text { moments automatically } \\
\text { throughout the day }\end{array}$ \\
\hline 6 & $\begin{array}{l}\text { Hartwell et al. } \\
2019 \text { [22] }\end{array}$ & 233 & FoodSmart App & $\begin{array}{l}\text { Enable informed consumer food choice, and } \\
\text { takes individual preferences as well as food } \\
\text { product specifications into account }\end{array}$ & $\begin{array}{l}\text { Provide tailored feedback and } \\
\text { appropriate format to enable } \\
\text { informed food choice out of } \\
\text { home }\end{array}$ \\
\hline 7 & $\begin{array}{l}\text { Lassen et al. } \\
2011[26]\end{array}$ & 27 & $\begin{array}{l}\text { A Canteen Take Away } \\
\text { (CTA) concept }\end{array}$ & $\begin{array}{l}\text { Provide free CTA and ready-to-heat meal to } \\
\text { help employees build a healthy eating } \\
\text { behavior during working hours }\end{array}$ & $\begin{array}{l}\text { Promote healthy eating } \\
\text { habits among employees }\end{array}$ \\
\hline 8 & $\begin{array}{l}\text { Matsushita \& } \\
\text { Kaneshima } \\
2019[30]\end{array}$ & $3+1$ & $\begin{array}{l}\text { Motion sensing } \\
\text { Eyewear Device }\end{array}$ & $\begin{array}{l}\text { A motion sensing device attached to } \\
\text { eyeglasses for monitoring daily activity }\end{array}$ & $\begin{array}{l}\text { Recognize daily activities } \\
\text { (eating. Working and other } \\
\text { activities) }\end{array}$ \\
\hline 9 & $\begin{array}{l}\text { Rahman et al. } \\
2014 \text { [36] }\end{array}$ & 14 & BodyBeat & $\begin{array}{c}\text { A novel mobile sensing system for capturing } \\
\text { and recognizing a diverse range of } \\
\text { non-speech body sounds in real-life } \\
\text { scenarios }\end{array}$ & $\begin{array}{l}\text { Recognize non-speech body } \\
\text { sounds (such as food intake, } \\
\text { breath) by capturing subtle } \\
\text { body vibrations }\end{array}$ \\
\hline 10 & $\begin{array}{l}\text { Rahman et al. } \\
2016 \text { [37] }\end{array}$ & 8 & $\begin{array}{l}\text { Wearable sensing } \\
\text { system }\end{array}$ & $\begin{array}{l}\text { Train detector via machine leaning with } \\
\text { personal eating data to predict about-to-eat } \\
\text { moments and trigger healthy eating } \\
\text { interventions prior to actual eating events }\end{array}$ & $\begin{array}{l}\text { Predict "about-to-eat" } \\
\text { moments and "time until the } \\
\text { next eating event" }\end{array}$ \\
\hline 11 & $\begin{array}{l}\text { Sysoeva et al. } \\
2017[42]\end{array}$ & 8 & $\begin{array}{l}\text { User-friendly } \\
\text { communication } \\
\text { channel }\end{array}$ & $\begin{array}{l}\text { Scan code from food product and provide } \\
\text { information about food items via text and } \\
\text { voice communication }\end{array}$ & $\begin{array}{l}\text { Know food batter and have a } \\
\text { good food choice }\end{array}$ \\
\hline 12 & $\begin{array}{l}\text { Thomaz et al. } \\
2013 \text { [45] }\end{array}$ & 5 & $\begin{array}{l}\text { First-person camera on } \\
\text { smartphone application }\end{array}$ & $\begin{array}{c}\text { Phone-based application that takes photos } \\
\text { automatically every } 30 \text { second to identify } \\
\text { eating moments in first-person } \\
\text { point-of-view images }\end{array}$ & $\begin{array}{l}\text { Recognize eating moments in } \\
\text { real-world settings }\end{array}$ \\
\hline 13 & $\begin{array}{l}\text { Thomaz et al. } \\
2015 \text { [44] }\end{array}$ & 21 & $\begin{array}{l}\text { Automated food intake } \\
\text { monitoring system }\end{array}$ & $\begin{array}{l}\text { Eating moment detection with } \\
\text { wrist-mounted inertial sensor from a } \\
\text { smartwatch }\end{array}$ & $\begin{array}{l}\text { Identify when eating } \\
\text { moments take place and } \\
\text { recognize eating or } \\
\text { non-eating time }\end{array}$ \\
\hline 14 & $\begin{array}{l}\text { Thomaz et al. } \\
2015 \text { [46] }\end{array}$ & 20 & $\begin{array}{l}\text { Sensor system with } \\
\text { acoustic sensor }\end{array}$ & $\begin{array}{c}\text { Eating activities are inferred from ambient } \\
\text { sounds captured with a wrist-mounted } \\
\text { device }\end{array}$ & Identify meal eating moments \\
\hline 15 & $\begin{array}{c}\text { Zhang \& } \\
\text { Amft } 2018 \\
\text { [54] }\end{array}$ & 10 & $\begin{array}{l}\text { Electromyography- } \\
\text { monitoring } \\
\text { Eyeglasses }\end{array}$ & $\begin{array}{l}\text { Identify eating moments in continuous } \\
\text { wearable sensor data }\end{array}$ & $\begin{array}{l}\text { Help to identify eating } \\
\text { moments automatically }\end{array}$ \\
\hline 16 & $\begin{array}{l}\text { Zhang et al. } \\
2021 \text { [53] }\end{array}$ & 53 & $\begin{array}{l}\text { Gamification app: } \\
\text { DMCoach+ }\end{array}$ & $\begin{array}{l}\text { Personal health gamification system to } \\
\text { promote occupational health conditions } \\
\text { with goal setting and remote coach }\end{array}$ & $\begin{array}{l}\text { Prevent occupational } \\
\text { eating-related health issues }\end{array}$ \\
\hline
\end{tabular}




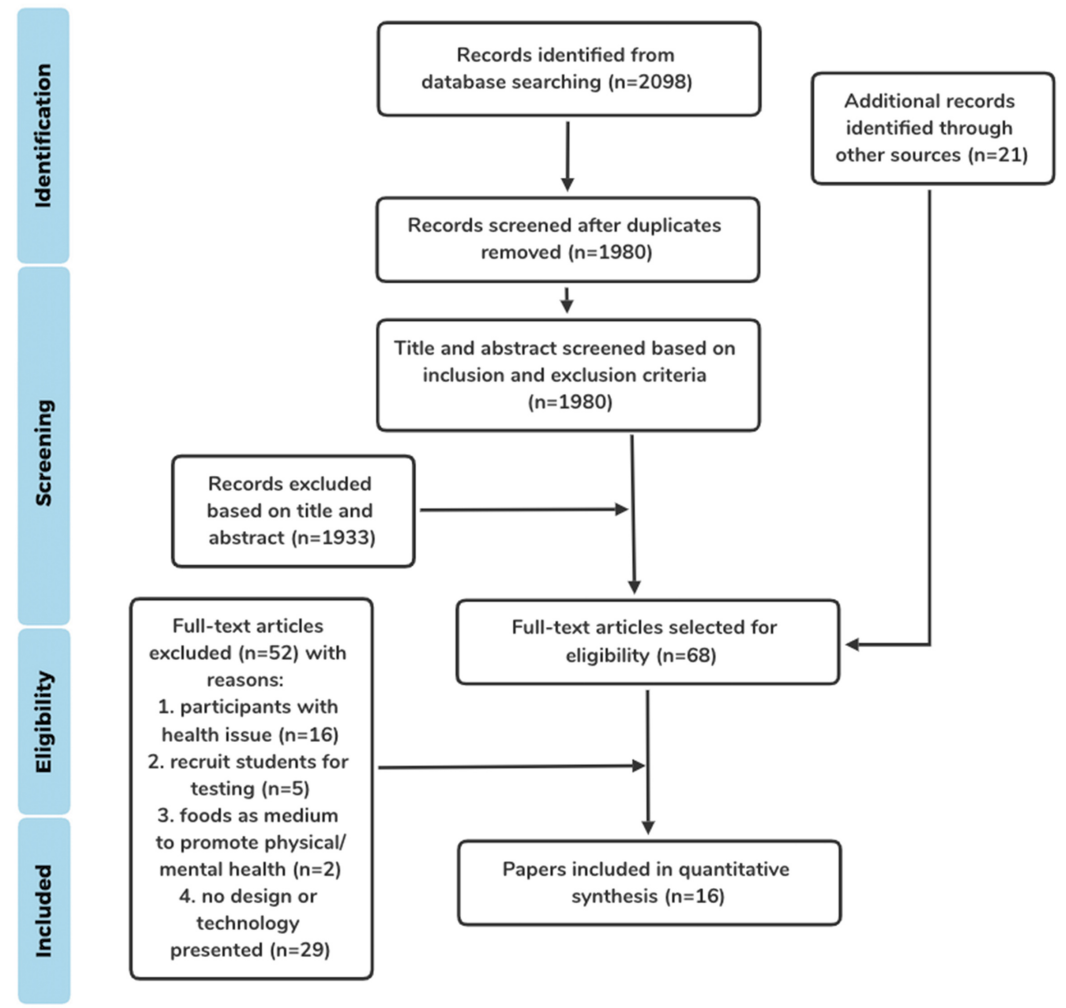

Figure 1: Flowchart of papers' selection based on PRISMA (Preferred Reporting Items for Systematic Reviews and MetaAnalyses).

Table 2: Objectives in the included technologies and designs.

\begin{tabular}{cc}
\hline Objectives & Included papers \\
\hline Identifying eating moments & {$[9,17,19,30,36,37,44-46,54]$} \\
Improving eating behavior & {$[1,13,22,26,42,53]$} \\
and promoting healthy food \\
choice
\end{tabular}

Theoretical Underpinning As shown in Table 3, many of the included papers did provide various approaches for promoting individual's healthy eating. However, few studies have specified behavior change techniques (BCT). Two studies [13, 22] used a digital tool with tailored feedback as BCT. One study [53] supported the user to set diet-related health goals and created the social support to promote healthy eating behaviors. The activity recognition model was used in five studies $[9,13,19,44,46]$. Six papers based on their technologies and designs on, respectively, monitoring of ingestive behavior [17], personal nutrition planner [1], machine learning model [37], human food interaction [42], social gamification system [53], and dietary self-monitoring [46].
Table 3: Theoretical underpinning used in the paper included in the analysis.

\begin{tabular}{cc}
\hline Theoretical underpinning & Included papers \\
\hline $\begin{array}{c}\text { Behavior change technique (tailored } \\
\text { feedback, goal setting, social }\end{array}$ & {$[13,22,53]$} \\
support) & \\
Human food interaction & {$[42]$} \\
Monitoring of ingestive behavior & {$[17]$} \\
Machine learning model & {$[37]$} \\
Personal nutrition planner & {$[1]$} \\
Recognition model & {$[9,13,19,44,46]$} \\
Social gamification system & {$[53]$} \\
Self-monitoring & {$[46]$} \\
Not specified & {$[26,30,36,45,54]$} \\
\hline
\end{tabular}

Design Approach According to the description of characteristics, 16 included papers adopted different design approaches, namely user-centered approach, technology-driven approach, and context-driven approach (as shown in Table 4). On the one hand, six included papers purely used one design approach. Specifically, two 
Table 4: Design approaches mentioned in the included papers.

\begin{tabular}{lc}
\hline Approach & Included papers \\
\hline User-centered approach & {$[1,22,26,37,42,53]$} \\
$\begin{array}{l}\text { Technology-driven } \\
\text { approach }\end{array}$ & {$[9,13,17,19,30,36,37,44,53,54-$} \\
Context-driven approach & $46]$ \\
\hline
\end{tabular}

papers [22, 42] developed design based on qualitative research and mainly focused on user-centered application to encourage healthy food choices. While five $[9,13,17,36,46]$ presented the setup and algorithm of technologies for intake detection. On the other hand, the rest ten included papers used mixed approaches. In particular, among these 10 papers, six [13, 19, 30, 44, 45, 54] mixed technologyand context-driven approaches, since the reported technologies were used in real-life daily settings (e.g. weekdays) instead lab experiment. Two $[1,26]$ combined user-centered and context-driven approaches, because the designs were mentioned for users' healthy food intake in the working context. In addition, the rest two papers used user-centered and tech-driven approaches. One of the two [37] technically detected users' daily intake and provided personalized suggestions at the meanwhile, while another one [53] merged technology with gamification to increase users' engagement of intake detection during working hours.

\subsection{Type of Technology and Design}

As shown in Table 5, several different types of technologies for healthy eating promotion during working hours were presented in the 16 included papers. The digital tools and design concepts included mobile applications [22, 42, 53], wearable devices [9, 17,
19, 30, 36, 44, 46, 54], office service [1, 26] and multicomponent (i.e., combination between app and wearable) [13, 37, 45].

Mobile Application Three included papers (18.75\%) designed mobile-based applications as a digital tool for healthy eating promotion. The main components of this type of technology were the interaction between users and foods, and tailored guidance for individual's promotion (such as goal setting, real-time interaction with foods, feedback, and advice). In addition to the specific components, two applications $[22,42]$ focused on encouraging healthy food choices via scanning the code on related foods or food-related objects (such as the package or the table). By doing so, users can have a good understanding of nutrient ingredients and gain tailored feedback. Moreover, one [53] paper focused on promoting occupational health via gamification and e-coaching. This mobile application supported users to set personal health goal and motivated users to achieve their goals via social competitions. Combining eating and physical activity, this application aimed to help users gain a healthy habit in daily life.

Wearable Eight papers (50\%) presented sensors-based wearables. Three of these studies used wrist-worn wearables [19, 44, 46], three used eye-worn wearables [17, 30, 54], one [9] used an earworn wearable, and one [36] used a neck-wearable. These eight papers aimed to measure eating time, while two of them [30, 44] also focused on detecting eating duration and one [19] on detecting eating frequency. In addition, each wearable depends on various sensors and measuring approaches. Specifically, six papers presented the means of detecting body movements, i.e., jaw movements [9], chewing [54], facial muscle activity and head motion [17, 30], wrist motion and gesture $[19,44]$. While eating activity was inferred from ambient sounds captured with acoustic sensor from the other two paper [36, 54].

Office Service Two of the 16 paper $(12.5 \%)$ provided service design to promote healthy eating in the working context. These two

Table 5: Types and examples of included technologies and designs.

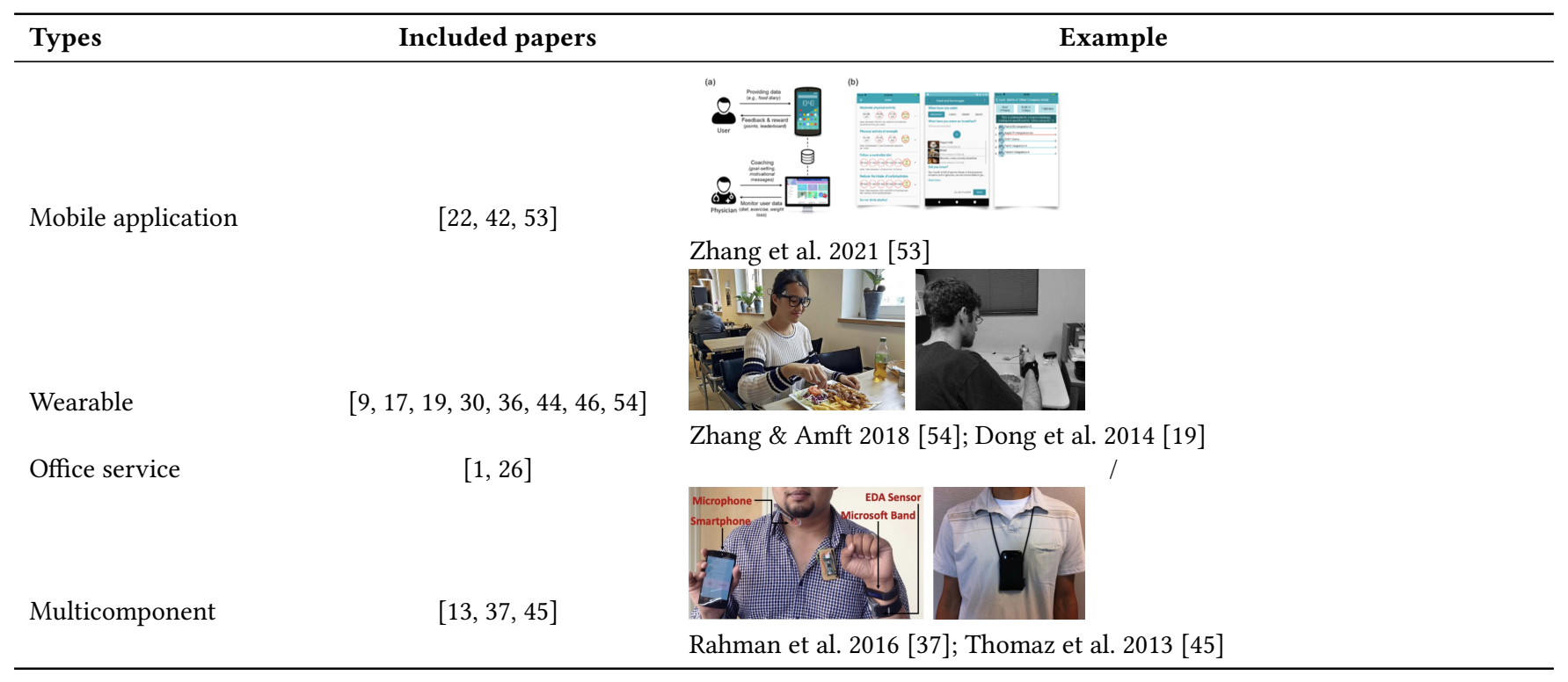


papers provided healthy food as the approach to improve eating habits and employees' health. In one study [1] fruits accessibility in the workplace was designed to encourage more healthy fruits and vegetable intake during working hours. Another study [26] provided ready-made take away meals with well-nutrient composition in the office canteen to promote healthy eating patterns among employees.

Multicomponent Three included papers (18.75\%) were designed with multiple digital tools. This multicomponent approach was identified as a combination between wearables and mobile applications. Two papers used wearables for measurement, and next a mobile application to provide food pattern, eating suggestions and feedback. Specifically, one paper [13] presented a digital system, which recognized food types by monitoring the eating process via an acoustic sensor and provided meal recognition accordingly to the user. In another paper [37] a machine learning algorithm was trained with user's eating data to predict about-to-eat moments to promote healthy eating habits. In one paper [45] a wearable smartphone was designed that could be worn in front of the body and capture daily routines and activities by images.

\section{DISCUSSION}

This scoping review is set out to gain a comprehensive understanding of digital technology and design for occupational health promotion. Through a literature search in Computing Machinery digital library, the interdisciplinary library Scopus, and the PubMed database, we identified and analyzed 16 selected papers published between 2010 and June 2021. This paper provided an overview of paper characteristics, including using digital technology and design objectives, theoretical underpinning, using contexts and types of digital technology for healthy eating promotion during working hours. The narrative analysis revealed two important gaps in current research as following.

Firstly, this review's two most common objectives were detecting daily eating moments and encouraging healthy food choices. Few papers aimed at behavior change purpose. Of the 16 included papers in this review, only three papers mentioned behavior change technique. Two papers $[22,42]$ developed user feedback mechanisms after measuring nutrients in foods using digital tools. One study [53] supported the user to set diet-related health goals and created the social support to promote healthy eating behaviors in the workplace. Other included papers presented, among others, dietary self-monitoring, personal nutrition planning, and machine learning modelling as techniques. Moreover, five included papers did not specify any techniques. The need of using BCTs in healthy eating was in line with previous work. For instance, the application of persuasive techniques could effectively increase users' awareness towards certain health behaviors [33]. Supporting goal-setting and facilitating goal-achieving activities could be useful to shape positive attitudes towards healthy lifestyles [51]. And human-computer interaction (HCI) for health also needs to embed BCTs to support long-term behavior change [41]. Therefore, in future design studies we suggest researchers to create digital tools for healthy eating promotion in working context through adopting various BCTs (e.g., tailored feedback, goal setting, rewards, social support, persuasion, self-reflection) [16].
Secondly, we found that the format of technology and design could be integrated into existing working infrastructures to increase user engagement. Only one paper employed office basket to supply free fruits in the workplace, while other papers mainly focused on personal technologies to promote healthy eating during work. According to prior studies, office workers may consider the wearable sensors too obtrusive to use in a working context for a long-term [32], and may abandon mobile applications because of too much effort required in work routines [27]. Some of our included papers in this scoping review also paid attention to easy and frequent use by reducing complexity of technology or design [13, 22]. This is in line with a number of existing technology and design concept. For instance, reducing prices on healthful snacks in office vending machines to increase healthy food choices [21]. In future research, it could be opportunity to examine whether integrating technology and design into working infrastructure will motivate people to use a digital tool. Using existing objects might reduce additional time requirement of users, which leads to an essential design opportunity in the health-promotion research field [34].

In addition, several included papers in this scoping review detected eating moments, frequency, and duration with digital tools. Some also focused on distinguishing eating time from other daily activities (e.g., working and talking). However, few specified digital tools to promote the dynamics between working routine and eating routine. In future research, promoting healthy eating in working routines could be a design opportunity. Maintained routines could help users balance the tension between working and eating in a real-life context [40,51]. Moreover, one included paper [53] used a gamification approach and another study [42] provided interactive communication to users as an efficient method to promote healthy eating. This is in line with other studies within HCI filed showing that playful tools could contribute to future eating-linked technology and could help users to engage in the technology [11, 47]. Thus, future design research could use gamification and playful human-computer interaction between eating and users to promote healthy eating in a working context. Besides, most of included papers used technology-driven approach to develop digital tools in working context, few papers focused on user-centered approach. Thus, future digital tools could involve user-centered design into healthy eating-related research.

This scoping review had some limitations. Firstly, by restricting our search from three databases, we might have excluded some relevant publications. Although we aimed to review technology and design for health eating promotion in a working context, a large number of papers addressed therapy-oriented tools or targeted at children and the elderly. Hence, we only included 16 papers in our final analysis. Secondly, three of the sixteen included papers specifically mentioned the type of keywords as "employee" and "workplace", while the rest papers were assumed by the reviewers, since the papers described working context and recruited workingage individuals as their participants. Thirdly, this is a scoping review, which aimed to qualitatively understand current digital tools and design opportunities for occupational healthy eating promotion without quantitative outcome analysis. Thus, in this review, digital tools are mainly linked to detecting eating time, eating frequency, eating duration, healthy food choices and healthy eating habits. The 
technologies and designs focused on nutrition intake measurements were not explicitly presented in the included papers.

\section{CONCLUSION}

This scoping review aimed to overview technologies and designs for promoting occupational healthy eating and identify design opportunities for future health-promoting digital tools that support healthy eating practices during working hours. The 16 included papers were published between 2010 and June 2021 in the fields of digital health, nutrition, human computation, wearables, sensors and mobile technology, and interactive system. Our review results revealed that current technologies and designs made limited use of existing working infrastructures. The second finding was that few digital tools for occupational healthy eating promotion addressed behavior change techniques in the developing process. Future design research could investigate interactive and playful digital tools with user-centered approach and behavior change techniques (e.g., rewards, persuasion, and self-reflection) to promote healthy eating behaviors and routines during working hours. We suggested that future studies could involve intake measurements into occupational healthy eating promotion, and more technologies and designs could be evaluated to show the effectiveness of outcomes.

\section{ACKNOWLEDGMENTS}

We thank all coauthors and advisers who took part in the studies. The first author is being sponsored by China Scholarship Council.

\section{REFERENCES}

[1] Alinia, S., Lassen, A.D., Krogholm, K.S., Christensen, T., Hels, O.H. and Tetens, I 2011. A workplace feasibility study of the effect of a minimal fruit intervention on fruit intake. Public health nutrition. 14, 8 (2011), 1382-1387.

[2] Allan, J., Querstret, D., Banas, K. and de Bruin, M. 2017. Environmental interventions for altering eating behaviours of employees in the workplace: a systematic review. Obesity Reviews. 18, 2 (2017), 214-226.

[3] Almaghrabi, R., Villalobos, G., Pouladzadeh, P. and Shirmohammadi, S. 2012 A novel method for measuring nutrition intake based on food image. 2012 IEEE I2MTC - International Instrumentation and Measurement Technology Conference, Proceedings. (2012), 366-370. DOI:https://doi.org/10.1109/I2MTC.2012. 6229581.

[4] Amft, O. 2008. Automatic dietary monitoring using on-body sensors: Detection of eating and drinking behaviour in healthy individuals.

[5] Amft, O., Stäger, M., Lukowicz, P. and Tröster, G. 2005. Analysis of chewing sounds for dietary monitoring. International Conference on Ubiquitous Computing (2005), 56-72.

[6] Amft, O. and Troster, G. 2006. Methods for detection and classification of normal swallowing from muscle activation and sound. 2006 Pervasive Health Conference and Workshops (2006), 1-10.

[7] Anderson, L.M., Quinn, T.A., Glanz, K., Ramirez, G., Kahwati, L.C., Johnson, D.B. Buchanan, L.R., Archer, W.R., Chattopadhyay, S. and Kalra, G.P. 2009. The effectiveness of worksite nutrition and physical activity interventions for controlling employee overweight and obesity: a systematic review. American journal of preventive medicine. 37, 4 (2009), 340-357.

[8] Arksey, H. and O'Malley, L. 2005. Scoping studies: Towards a methodological framework. International Journal of Social Research Methodology: Theory and Practice. 8, 1 (2005), 19-32. DOI:https://doi.org/10.1080/1364557032000119616.

[9] Bedri, A., Verlekar, A., Thomaz, E., Avva, V. and Starner, T. 2015. A wearable system for detecting eating activities with proximity sensors in the outer ear ISWC 2015 - Proceedings of the 2015 ACM International Symposium on Wearable Computers. (2015), 91-92. DOI:https://doi.org/10.1145/2802083.2808411.

[10] Benedict, M.A. and Arterburn, D. 2008. Worksite-based weight loss programs: a systematic review of recent literature. American Journal of Health Promotion. 22, 6 (2008), 408-415.

[11] Bertran, F.A., Wilde, D., Berezvay, E. and Isbister, K. 2019. Playful human-food interaction research: State of the art and future directions. CHI PLAY 2019 Proceedings of the Annual Symposium on Computer-Human Interaction in Play (2019), 225-237.
[12] Bi, S., Wang, T., Davenport, E., Peterson, R., Halter, R., Sorber, J. and Kotz, D. 2017. Toward a wearable sensor for eating detection. WearSys 2017 - Proceedings of the 2017 Workshop on Wearable Systems and Applications, co-located with MobiSys 2017 (2017), 17-22.

[13] Bi, Y., Lv, M., Song, C., Xu, W., Guan, N. and Yi, W. 2015. AutoDietary: A Wearable Acoustic Sensor System for Food Intake Recognition in Daily Life. IEEE Sensors Journal. 16, 3 (2015), 806-816. DOI:https://doi.org/10.1109/JSEN.2015.2469095.

[14] Branca, F., Nikogosian, H. and Lobstein, T. 2007. The challenge of obesity in the WHO European Region and the strategies for response: summary. World Health Organization.

[15] Cahalin, L.P., Kaminsky, L., Lavie, C.J., Briggs, P., Cahalin, B.L., Myers, J., Forman, D.E., Patel, M.J., Pinkstaff, S.O. and Arena, R. 2015. Development and implementation of worksite health and wellness programs: a focus on non-communicable disease. Progress in cardiovascular diseases. 58, 1 (2015), 94-101.

[16] Cheng Chia, G.L., Anderson, A. and McLean, L.A. 2019. Behavior change techniques incorporated in fitness trackers: Content analysis. JMIR mHealth and uHealth. 7, 7 (2019). DOI:https://doi.org/10.2196/12768.

[17] Chung, J., Chung, J., Oh, W., Yoo, Y., Lee, W.G. and Bang, H. 2017. A glasses-type wearable device for monitoring the patterns of food intake and facial activity. Scientific Reports. 7, December 2016 (2017), 1-8. DOI:https://doi.org/10.1038/ srep41690.

[18] Close, M.A., Lytle, L.A., Chen, D.-G. and Viera, A.J. 2018. Using the theory of planned behavior to explain intention to eat a healthful diet among Southeastern United States office workers. Nutrition \& Food Science. (2018).

[19] Dong, Y., Scisco, J., Wilson, M., Muth, E. and Hoover, A. 2014. Detecting periods of eating during free-living by tracking wrist motion. IEEE Journal of Biomedical and Health Informatics. 18, 4 (2014), 1253-1260. DOI:https://doi.org/10.1109/JBHI. 2013.2282471.

[20] Evans, D. 2017. MyFitnessPal. Br J Sports Med. 51, 14 (2017), 1101-1102.

[21] French, S.A., Jeffery, R.W., Story, M., Breitlow, K.K., Baxter, J.S., Hannan, P. and Snyder, M.P. 2001. Pricing and promotion effects on low-fat vending snack purchases: the CHIPS Study. American journal of public health. 91, 1 (2001), 112.

[22] Hartwell, H., Appleton, K.M., Bray, J., Price, S., Mavridis, I., Giboreau, A., PerezCueto, F.J.A. and Ronge, M. 2019. Shaping smarter consumer food choices: The FoodSMART project. Nutrition Bulletin. 44, 2 (2019), 138-144. DOI:https://doi. org $/ 10.1111 /$ nbu.12376.

[23] He, S., Li, S., Nag, A., Feng, S., Han, T., Mukhopadhyay, S.C. and Powel, W. 2020. A comprehensive review of the use of sensors for food intake detection. Sensors and Actuators, A: Physical. 315, (2020). DOI:https://doi.org/10.1016/j.sna.2020.112318.

[24] Higgins, J.P. 2016. Smartphone applications for patients' health and fitness. The American journal of medicine. 129, 1 (2016), 11-19.

[25] Junker, H., Amft, O., Lukowicz, P. and Tröster, G. 2008. Gesture spotting with body-worn inertial sensors to detect user activities. Pattern Recognition. 41, 6 (2008), 2010-2024.

[26] Lassen, A.D., Ernst, L., Poulsen, S., Andersen, K.K., Hansen, G.L., Biltoft-Jensen, A. and Tetens, I. 2012. Effectiveness of a Canteen Take Away concept in promoting healthy eating patterns among employees. Public health nutrition. 15, 3 (2012), 452-458.

[27] Lazar, A., Koehler, C., Tanenbaum, J. and Nguyen, D.H. 2015. Why we use and abandon smart devices. UbiComp 2015 - Proceedings of the 2015 ACM International Joint Conference on Pervasive and Ubiquitous Computing. (2015), 635-646. DOI:https://doi.org/10.1145/2750858.2804288.

[28] Maes, L., Van Cauwenberghe, E., Van Lippevelde, W., Spittaels, H., De Pauw, E., Oppert, J.-M., Van Lenthe, F.J., Brug, J. and De Bourdeaudhuij, I. 2012. Effectiveness of workplace interventions in Europe promoting healthy eating: a systematic review. European journal of public health. 22, 5 (2012), 677-683.

[29] Martin, C.K., Nicklas, T., Gunturk, B., Correa, J.B., Allen, H.R. and Champagne, C. 2014. Measuring food intake with digital photography. Journal of Human Nutrition and Dietetics. 27, SUPPL.1 (2014), 72-81. DOI:https://doi.org/10.1111/ jhn.12014.

[30] Matsushita, S. and Kaneshima, R. 2019. Motion sensing eyewear for daily healthcare monitoring. 2019 IEEE 8th Global Conference on Consumer Electronics, GCCE 2019. (2019), 925-928. DOI:https://doi.org/10.1109/GCCE46687.2019. 9015301

[31] Moher, D., Liberati, A., Tetzlaff, J., Altman, D.G. and Group, P. 2009. Preferred reporting items for systematic reviews and meta-analyses: the PRISMA statement. PLoS medicine. 6, 7 (2009), e1000097.

[32] Neil, D., Lapierre, N., Bal, H., Perrault, S., Parker, D. and Reilly, D. 2013. Limber: Exploring motivation in a workplace exergame. Proceedings of the ACM Conference on Computer Supported Cooperative Work, CSCW. (2013), 239-242. DOI:https://doi.org/10.1145/2441955.2442013.

[33] Orji, R. and Moffatt, K. 2018. Persuasive technology for health and wellness: State-of-the-art and emerging trends. Health informatics journal. 24, 1 (2018), 66-91.

[34] Patrick, K., Hekler, E.B., Estrin, D., Mohr, D.C., Riper, H., Crane, D., Godino, J. and Riley, W.T. 2016. The pace of technologic change: implications for digital health behavior intervention research. Elsevier. 
[35] Ouintiliani, L., Poulsen, S. and Sorensen, G. 2010. Healthy eating strategies in the workplace. International Journal of Workplace Health Management. 3 , 3 (2010) 182-196. DOI:https://doi.org/10.1108/17538351011078929.

[36] Rahman, T., Adams, A.T., Zhang, M., Cherry, E., Zhou, B., Peng, H. and Choudhury, T. 2014. BodyBeat: A mobile system for sensing non-speech body sounds. MobiSys 2014 - Proceedings of the 12th Annual International Conference on Mobile Systems, Applications, and Services. (2014), 2-13. DOI:https://doi.org/10.1145/ 2594368.2594386

[37] Rahman, T., Czerwinski, M., Gilad-Bachrach, R. and Johns, P. 2016. Predicting "about-To-eat" moments for just-in-Time eating intervention. DH 2016 - Proceedings of the 2016 Digital Health Conference. (2016), 141-150. DOI:https //doi.org/10.1145/2896338.2896359.

[38] Siegel, J.A. and Sawyer, K.B. 2019. Eating disorders in the workplace: A qualitative investigation of women's experiences. Psychology of Women Quarterly. 43, 1 (2019), 37-58.

[39] Soler, R.E. et al. 2010. A Systematic Review of Selected Interventions for Worksite Health Promotion. The Assessment of Health Risks with Feedback. American Journal of Preventive Medicine. 38, 2 SUPPL. (2010), S237-S262. DOI:https://doi. org/10.1016/j.amepre.2009.10.030

[40] Spahn, J.M., Reeves, R.S., Keim, K.S., Laquatra, I., Kellogg, M., Jortberg, B. and Clark, N.A. 2010. State of the evidence regarding behavior change theories and strategies in nutrition counseling to facilitate health and food behavior change. Journal of the American Dietetic Association. 110, 6 (2010), 879-891.

[41] Stawarz, K.M. and Cox, A.L. 2015. Designing for health behavior change: $\mathrm{HCI}$ research alone is not enough. CHI'15 workshop: Crossing HCI and Health: Advancing Health and Wellness Technology Research in Home and Community Settings (2015)

[42] Sysoeva, E., Zusik, I. and Symonenko, O. 2017. Food-to-person interaction: How to get information about what we eat? DIS 2017 Companion - Proceedings of the 2017 ACM Conference on Designing Interactive Systems. (2017), 106-110. DOI:https://doi.org/10.1145/3064857.3079128.

[43] Thomas, J. and Harden, A. 2008. Methods for the thematic synthesis of qualitative research in systematic reviews. BMC medical research methodology. 8, 1 (2008), $1-10$.
[44] Thomaz, E., Essa, I. and Abowd, G.D. 2015. A practical approach for recognizing eating moments with wrist-mounted inertial sensing. (2015), 1029-1040. DOI:https://doi.org/10.1145/2750858.2807545.

[45] Thomaz, E., Parnami, A., Essa, I. and Abowd, G.D. 2013. Feasibility of identifying eating moments from first-person images leveraging human computation. Proceedings of the 4 th International SenseCam \& Pervasive Imaging Conference (2013), 26-33.

[46] Thomaz, E., Zhang, C., Essa, I. and Abowd, G.D. 2015. Inferring meal eating activities in real world settings from ambient sounds: A feasibility study. International Conference on Intelligent User Interfaces, Proceedings IUI. 2015-Janua, (2015), 427-431. DOI:https://doi.org/10.1145/2678025.2701405.

[47] Tondello, G.F. 2016. An introduction to gamification in human-computer interaction. XRDS: Crossroads, The ACM Magazine for Students. 23, 1 (2016), 15-17.

[48] Upadhyaya, M., Sharma, S., Pompeii, L.A., Sianez, M. and Morgan, R.O. 2020. Obesity prevention worksite wellness interventions for health care workers: A narrative review. Workplace health \& safety. 68, 1 (2020), 32-49.

[49] Verweij, L.M., Coffeng, J., van Mechelen, W. and Proper, K.I. 2011. Meta-analyses of workplace physical activity and dietary behaviour interventions on weight outcomes. Obesity reviews. 12, 6 (2011), 406-429.

[50] Vu, T., Lin, F., Alshurafa, N. and Xu, W. 2017. Wearable food intake monitoring technologies: A comprehensive review. Computers. 6, 1 (2017). DOI:https://doi. org $/ 10.3390 /$ computers6010004.

[51] West, J.H., Belvedere, L.M., Andreasen, R., Frandsen, C., Hall, P.C. and Crookston, B.T. 2017. Controlling your "app" etite: how diet and nutrition-related mobile apps lead to behavior change. JMIR mHealth and uHealth. 5, 7 (2017), e95.

[52] Wohlin, C. 2014. Guidelines for Snowballing in Systematic Literature Studies and a Replication in Software Engineering. (2014).

[53] Zhang, C., Van Gorp, P., Derksen, M., Nuijten, R., IJsselsteijn, W.A., Zanutto, A., Melillo, F. and Pratola, R. 2021. Promoting Occupational Health through Gamification and E-Coaching: A 5-Month User Engagement Study. International Journal of Environmental Research and Public Health. 18, 6 (2021), 2823.

[54] Zhang, R. and Amft, O. 2018. Free-living eating event spotting using EMGmonitoring eyeglasses. 2018 IEEE EMBS International Conference on Biomedical and Health Informatics, BHI 2018. 2018-Janua, March (2018), 128-132. DOI:https://doi.org/10.1109/BHI.2018.8333386. 